American Journal of Pharmaceutical Education 2017; 81 (1) Article 10.

\title{
RESEARCH
}

\section{Pharmacy Interns' Perception of Their Professional Role}

\author{
Stense Vestergaard, MPH, Lotte Stig Nørgaard, PhD, Janine Marie Traulsen, Susanne Kaae, PhD \\ University of Copenhagen, Copenhagen, Denmark \\ Submitted September 18, 2015; accepted May 23, 2016; published February 25, 2017.
}

\begin{abstract}
Objective. To determine pharmacy interns' perceptions of the roles of the pharmacist and pharmacy prior to and during the pharmacy internship and to compare their perceptions with those of their supervisors and the pharmacy customers.

Methods. Questionnaires were completed and submitted by 395 interns prior to and during their internships. Interns interviewed their supervisors and two to four local customers.

Results. Ninety-six supervisors and 285 customers were interviewed. Interns' perceptions were aligned with those of their supervisors in that both groups indicated that a pharmacist's most important role is that of a clinical leader. Furthermore, interns' perception of customers' expectations regarding the pharmacy were well aligned with customers' actual expectations with regard to service.

Conclusion. The study illustrates that interns became more aligned in their perceptions due to the pharmacy internship. The study findings imply that the pharmacy internship influences interns' perception of the pharmacy and pharmacist's roles in society through complex individual and social learning processes.
\end{abstract}

Keywords: pharmacy internship, Denmark, attitudes, role perception

\section{INTRODUCTION}

The success of any profession lies in its contribution to society. Education is considered a key element in any profession, because it defines existing values and norms about how the learned skills should be practiced. Education is thus expected to play a role in forming interns' attitude toward the primary roles of a specific profession.

Despite efforts to educate pharmacists to serve pharmacy users and society, there appears to be at least two conflicting views of pharmacy and the role of the pharmacist. On the one hand, pharmacies are viewed as local health care centers (the public's first contact with the health care system) and pharmacists are viewed as the most easily accessible health care professionals. In this view, the pharmacy sector contributes to public health and ensures customer safety. ${ }^{1}$ Both pharmacists and customers seem to hold this view. ${ }^{2}$ On the other hand, some decision-makers and customers view pharmacies as commercial enterprises and pharmacists as business people. ${ }^{2}$

This discrepancy in perceptions has shed light on the need for pharmacies to adopt more patient-oriented services. For example, some pharmacy customers are reluctant to

Corresponding Author: Lotte Stig Nørgaard, the University of Copenhagen, the Faculty of Health and Medical Sciences, Department of Pharmacy, Section for Social and Clinical Pharmacy, Universitetsparken 2, 2100 Copenhagen, Denmark. Tel: 0045 21309602. E-mail: lotte.norgaard@sund.ku.dk allow pharmacists to support them in monitoring their medical treatment and even avoid or decline pharmacy counseling. ${ }^{3-4}$ Little is known about the factors that contribute to the development of these differences and whether pharmacists are aware that their priorities and customers' priorities differ.

Education seems to play a role in at least the creation of pharmacy interns' positive attitudes toward providing patient counseling. The combination of academic pharmacy education (formal learning) and practical experience in pharmacy work obtained through internship placements (informal learning) has led to pharmacy interns having positive attitudes toward providing counseling in pharmacies. ${ }^{5-6}$ However, the literature has also stated that further studies on the importance of the entire social context for learning are needed. ${ }^{7}$ Special counseling programs applied during pharmacy internships have also been shown to improve interns' views about pharmacists' counseling role. ${ }^{8}$ The underlying mechanisms by which pharmacy internships influence interns' views about pharmacists' role in counseling patients have not been explored, neither in terms of whether these acquired attitudes continue into post-educational practices nor in terms of how a potential gap in regard to customer perceptions is created.

A design in which pharmacy interns serve as the primary data collectors for a national research project was used successfully at the University of Copenhagen with the aim of both conducting relevant research and 


\section{American Journal of Pharmaceutical Education 2017; 81 (1) Article 10.}

supporting the learning of pharmacy interns. ${ }^{9}$ Hence, this type of design was adopted here primarily to allow for a large number of participants nationwide.

Prior to their internship, interns have been provided with limited information about community pharmacy. This is because more than $60 \%$ of pharmacists in Denmark work in the pharmaceutical industry, while only approximately $15 \%$ work in community pharmacy. This percentage distribution is mirrored in the pharmacy curriculum, as the majority of the courses provided prior to the pharmacy internship are related to natural science such as biology, pharmacology, drug development, and formulation. Pharmacy students visit a pharmacy on a single day during their undergraduate years, and complete a two-day course about community pharmacy (and hospital pharmacy) a few days prior to starting their internship. In addition, prior to their internship, interns complete two social pharmacy courses; however, these courses focus on societal, group-related, and individual social pharmacy aspects rather than on organizational aspects of pharmacy.

To better understand how the internship influences interns' views of the role of the pharmacy, we considered the learning theories described below. According to Wallman, ${ }^{10}$ learning during pharmacy internship can be categorized according to one of the following three different perspectives: acquisition, participation, or a combination of the two. Learning as acquisition implies that the individual possesses and is aware of the activity, whereas learning as participation implies an ongoing process that is produced and constantly reconstructed through relationships and interactions. Hence, from a participatory point of view, knowledge is not something individually "possessed"; rather, it is a social construction. ${ }^{11}$

The Swiss educational learning-as-participation theorist and practitioner Etienne Wenger ${ }^{12}$ states that, in practice, learning is a combination of the following four subtypes: learning as doing (practice, ie, what are we doing?); learning as belonging (community, ie, where do we belong?); learning as becoming (identity, ie, who are we becoming?); learning as experience (meaning, ie, what is our experience?).

Basically, learning is a foundation of what it means to be human. Another vital aspect of internships is what Wenger and Lave ${ }^{13}$ call "legitimate peripheral participation," through which newcomers learn through active interaction with more experienced individuals in the community of practice. ${ }^{10,13}$ The term legitimate indicates that the learner is accepted as a member of the working community, and peripheral participation is defined as the opposite of full participation. During the pharmacy internship, interns are incorporated into this type of situated learning context; thus, their sense of professionalism is highly influenced by the community in which they are allocated. Interns are expected to understand and grasp the content and historical development of their community (in this case, the pharmacy). ${ }^{14}$

Based on the above considerations, we expect interns to learn primarily through a process of learning as participation, in particular, "legitimate peripheral participation," during their internship. This process is in line with one of our previous Danish pharmacy internship studies. $^{15}$

This study analyzed and discussed the development of pharmacy interns' attitudes regarding pharmacy and the role of the pharmacist prior to and during their internship. Furthermore, the interns' perceptions are compared with those of their supervisors and with customers' expectations of the pharmacy. By defining expectations as beliefs that are related to the future and satisfaction as the degree to which these expectations are met, we make a clear distinction between the two concepts. ${ }^{16}$

\section{METHOD}

Similar to all other health professionals, pharmacy students receive supervised practical training as a mandatory part of their curriculum. The pharmacy internship is a cornerstone in the education of pharmacists in European countries as it brings interns in contact with the users of health care and pharmacy services.

In 2010, 2011, and 2012, all 395 pharmacy interns enrolled at the University of Copenhagen were invited to participate in a study that aimed to explore the development of interns' positive attitudes toward the roles of the pharmacy and the pharmacist and to assess how these attitudes become unaligned with those of pharmacy customers. The internship ran from February until July. Interns were asked to complete identical questionnaires prior to their internship (January) and late in their internship (May). The questionnaires covered the following areas: their attitudes toward the most important tasks of community pharmacies; their attitudes toward the most important tasks of community pharmacists; and their perceptions of customers' expectations of pharmacy staff members.

We chose to collect data using a questionnaire because it allowed us to directly compare interns' attitudes prior to and late in the internship and, thus, assess the development of their attitudes. We perceived that interns lacked precise notions of the actual tasks of the pharmacy and pharmacists prior to the internship (see Introduction), which prompted us to ask prompting questions.

Each of the three areas described above were addressed by 12-14 multiple-choice questions, with 


\section{American Journal of Pharmaceutical Education 2017; 81 (1) Article 10.}

different response options. The specific items were inspired by core pharmacist tasks, as described in "Pharmacy Practice Activity Classification - a classification of the activities of licensed practicing pharmacists across the continuum of health care delivery systems," which was developed in the US ${ }^{17}$ and adapted to the Danish pharmacy context. Interns were asked to select a maximum of four items that they thought most adequately expressed their attitudes or perceptions.

The questions related to the most important tasks of pharmacy and pharmacists and interns' perceptions of customers' expectations can be categorized into the following four overall themes: clinical professional task, organizational task, societal task, and service task. For the distribution of the different items across the four task themes, see Tables 1-3.

To assess whether interns' attitudes toward the roles of pharmacies and pharmacists and their perceptions of customers' expectations resembled those of practicing pharmacists and pharmacy customers, the study was expanded in 2011 and 2012 to include interviews with supervisors and customers. Interns were asked to interview both their pharmacy supervisor and two to four local customers regarding their attitudes toward the role of the pharmacy. Local supervisors in this context were assumed to represent existing norms and attitudes of pharmacy staff and the profession, whereas customers were assumed to represent the norms and attitudes of those in the context surrounding the pharmacy.

The interview guides for both supervisors and customers included open-ended questions to capture the interviewees' spontaneous and unbiased attitudes and experiences. The supervisors were specifically asked about (1) what they considered to be their most important tasks as pharmacists, and (2) their perceptions of customers' expectations of the pharmacy. In addition, interns interviewed two to four randomly selected customers at the counter of their internship pharmacy. These interviews typically took place directly after the customer had purchased either prescription or nonprescription medicine. The interview explored customers' expectations of the pharmacy and pharmacy staff members. Customers were also asked more in-depth questions about their previous experiences with pharmacy counseling, such as their expectations of the staff members who asked questions and whether the dialogues initiated by the questions led to fruitful outcomes. These results have been reported elsewhere. ${ }^{18}$

Interns were asked to record and transcribe supervisors' and customers' answers or to take extensive notes from the dialogues. The estimated duration of each interview was 10 minutes.
For the first step in the analyses, we registered interns' responses and calculated the average percentage of the two points. The influence of pharmacy internship training on interns' development of positive attitudes toward the pharmacy's extended role in providing counseling was then assessed by comparing the answers provided before the internship to the answers given late in the internship. The learning process was interpreted through the perspective of the theories developed by Wallmann ${ }^{10}$ and Wenger. ${ }^{12}$ Answers were analyzed according to the four themes described above: clinical professional services, organizational tasks, societal tasks and service orientation of staff.

The data from the interviews with supervisors and customers were subjected to a thematic analysis regarding attitudes toward and/or expectations of the roles of the pharmacy and pharmacists. Regarding customers' expectations of the pharmacy and supervisors' perception of customers' expectations, the statements from the interviews were coded into the following six themes: clinical professional services, appealing attitude of staff, waiting time, medicine in stock, adequate interior, and no particular expectation.

To validate the construction of themes and the analysis process, the authors discussed the identified patterns until they reached a consensus. The percentages of answers pertaining to the developed themes were then calculated so that the answers could be compared with the items and themes identified in the survey.

Pharmacy interns' attitudes toward the most important tasks that pharmacists perform were then compared to those of their local supervisors. Furthermore, the perceptions that interns developed during the internship in regard to customers' expectations of pharmacies were compared with the perceptions of supervisors and the views expressed by the customers.

\section{RESULTS}

The number of interns who participated in the survey prior to the internship was 131 in 2010, 151 in 2011, and 113 in 2012, and the number of interns who responded late in the internship was 146 in 2010, 116 in 2011, and 124 in 2012. The number of supervisors who participated in the study was 38 in 2011 and 58 in 2012 (no supervisors were involved in the study in 2010). The number of customers who were interviewed was 108 in 2011 and 177 in 2012 (no patient interviews were carried out in 2010).

The interns' answers regarding pharmacies' most important tasks showed movement in both directions. The number of answers declined and increased for six in 2011 and seven questions in 2012. "Administration of reimbursement" remained the same (4\%) (Table 1). 
American Journal of Pharmaceutical Education 2017; 81 (1) Article 10.

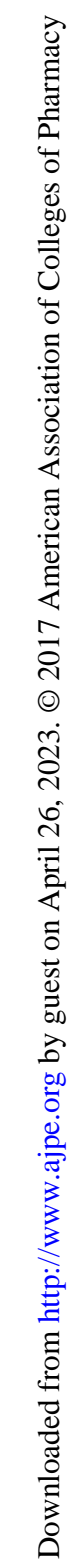

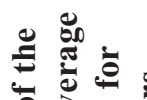

$+\sum_{0}^{\circ}$

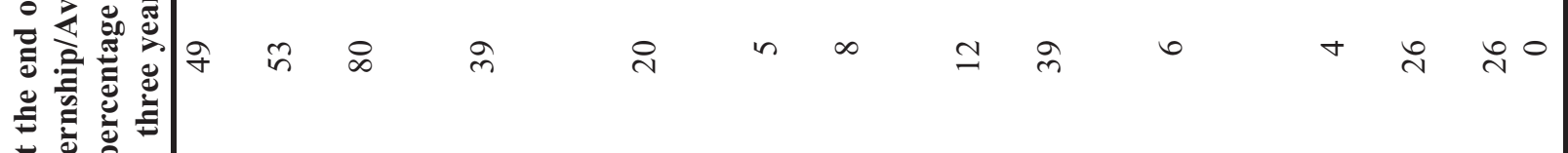

递要

告

ข

$\sin$

$\infty$

in

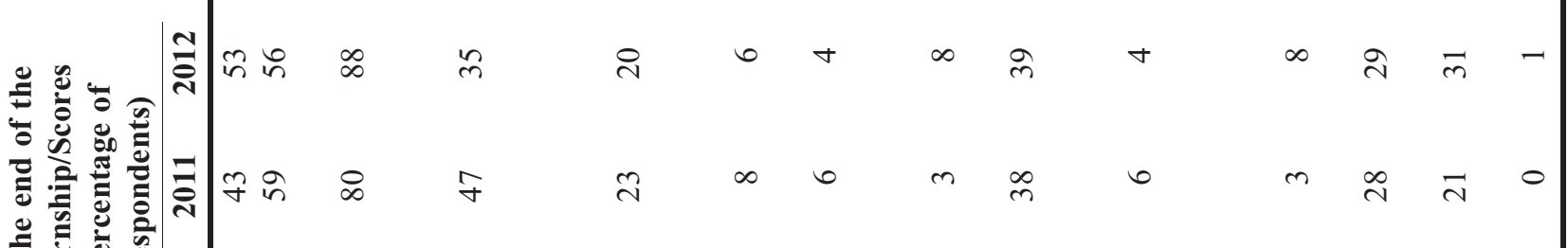

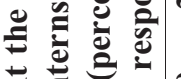

을

的

$\infty \quad \cdots$

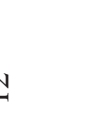

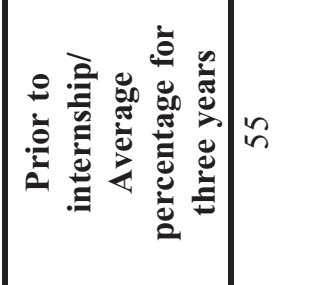

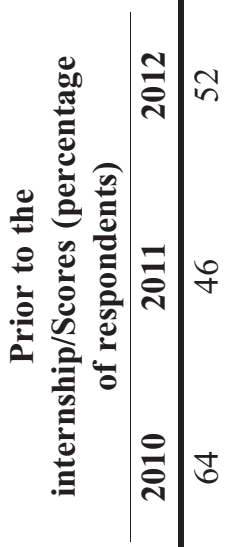

굥

$\stackrel{+}{+}$

$\simeq \stackrel{\infty}{=}$

in

$\sim$

$m$ ले \pm-

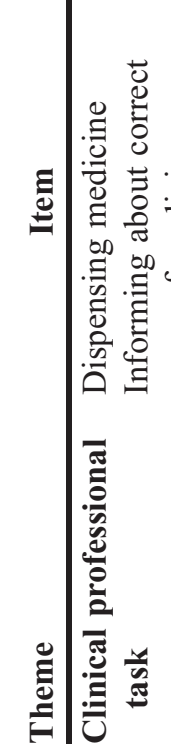

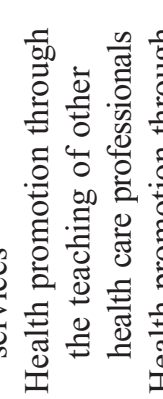

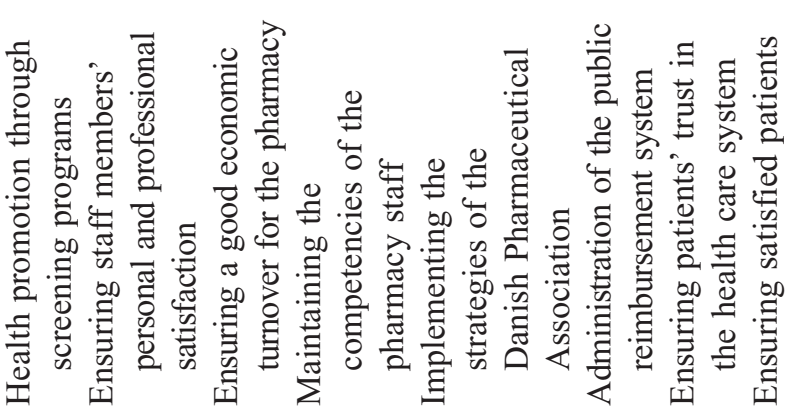

离

పั

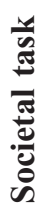

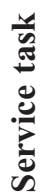




\section{American Journal of Pharmaceutical Education 2017; 81 (1) Article 10.}

Regarding interns' perception of pharmacists' most important tasks, the overall picture is the same. Thus, five and six questions, respectively, displayed an increasing and declining percentage of answers. "Ensuring positive economic turnover" remained the same/stable (5\%) (Table 2).

Prior to the internship, interns expressed that professional "clinical" tasks were the most important tasks that pharmacies and pharmacists performed. Hence, the themes of "Ensuring correct medical treatment through active dialogue at the counter" (73\%) and "Informing about correct use of medicine" $(65 \%)$ received the highest scores with regard to the most important tasks of community pharmacies (Table 1). Similarly, with regard to the main tasks of community pharmacists, "being responsible for the QA processes" (76\%) and "being a clinical leader" (71\%) received the highest scores (Table 2).

By the end of the internship, interns had become more aware of the business aspects of pharmacy work, ie, the administrative and "day-to-day" activities in the pharmacy. Interns ranked the most important clinical professional tasks that pharmacies and pharmacists perform in the same order: "ensuring correct medical treatment through active dialogue at the counter" $(80 \%)$ and "informing about correct use of medicine (53\%) for pharmacies (Table 1) and "being a clinical leader" $(81 \%)$ and "being responsible for QA processes" (73\%) for pharmacists (Table 2). However, not all aspects of the clinical professional task remained prioritized, as "ensuring patients' optimal medical treatment" was reduced from $64 \%$ to $46 \%$, and the second highest-rated answer, "Informing about correct use of medicine," was reduced by $12 \%$ (Table 2). Another noteworthy change was the reduction in the societal task item "Ensuring patients' trust in the health care system" by nearly $20 \%$, from $45 \%$ to $26 \%$ (Table 1).

Interns' perceptions of customers' expectations showed the least change over time. Thus, three questions had the same percentage of answers at both time points, and only two of the 13 answers displayed changes greater than five percentage points. Similarly, only five of the 14 and four of the 12 answers concerning pharmacies' and pharmacists' most important tasks (Tables 1 and 2), respectively, exhibited changes greater than five percentage points. The following items received the highest scores in terms of interns' perceptions of customers' expectations of pharmacies prior to the internship: "Staff dispenses medicines quickly" (77\%), "Staff has extensive knowledge about medicine" (76\%), and "Staff is serviceminded - smiling and friendly" (75\%) (Table 3). Thus, "service" was important. Interns' responses regarding "Staff has extensive knowledge about medicine," decreased by nine percentage points over the course of the internship; however, the other two items remained relatively stable. Despite the decline, the interns perceived "clinical professional service" as most important for customers' experience.

Slightly more than half of the most explicit changes reported appear to be general tendencies throughout the years, such as the increasing percentage of interns selecting "Being an administrative leader" and "Being a clinical leader" and the decreasing percentage selecting "Ensuring patients' optimal medical treatment" and "Networking" (Table 2).

Other changes were explained by mixed patterns of movement. For example, the increase in respondents who chose "Ensuring a good economic turnover," from 5\% to $12 \%$, was the result of a decline in one year (2011) and increase in two years (Table 1). Table 3 presents the major changes with regard to "Staff is committed to helping the patient" (from 51\% to 42\%) and "Staff has extensive knowledge about medicine" (from 76\% to 67\%). In both cases, the interns' answers in 2011 moved in the opposite direction.

Interns were aligned with the attitudes of their supervisors in that both groups rated "Being a clinical leader" as pharmacists' most important task (Table 4).

Supervisors expressed that they believed "Being a clinical leader" was, by far, the most important task (92\% in 2011 and 95\% in 2012), followed by "Being an administrative leader" (34\% in 2011 and $42 \%$ in 2012). Interns, however, rated "being an administrative leader" considerably lower than did their supervisors, despite an increase in their opinion during the internship period from $12 \%-22 \%$ to $28 \%-34 \%$ (Table 2 ).

In contrast to their supervisors, interns assumed that customers expect service. Thus, interns perceived that customers rate service high, both prior to and at the end of the internship. Supervisors slightly overestimated customers' expectations of "clinical" services in both 2011 and 2012 , with a difference of $3 \%$ and $12 \%$, respectively, and they largely underestimated customers' perception of "service," with a difference of $40 \%$ and $38 \%$ in 2011 and 2012, respectively.

\section{DISCUSSION}

This study shows that - both prior to and at the end of the internship - interns perceived clinical tasks as being highly important. Supervisors and interns both ranked being a clinical leader high. This finding is in line with Wenger's " "learning as becoming" categorization because, in contrast to the typical pharmacy technicians/ pharmaconomists, pharmacy interns are expected to become clinical leaders. A discrepancy was identified both 
American Journal of Pharmaceutical Education 2017; 81 (1) Article 10.

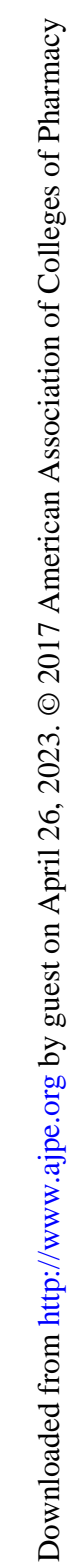

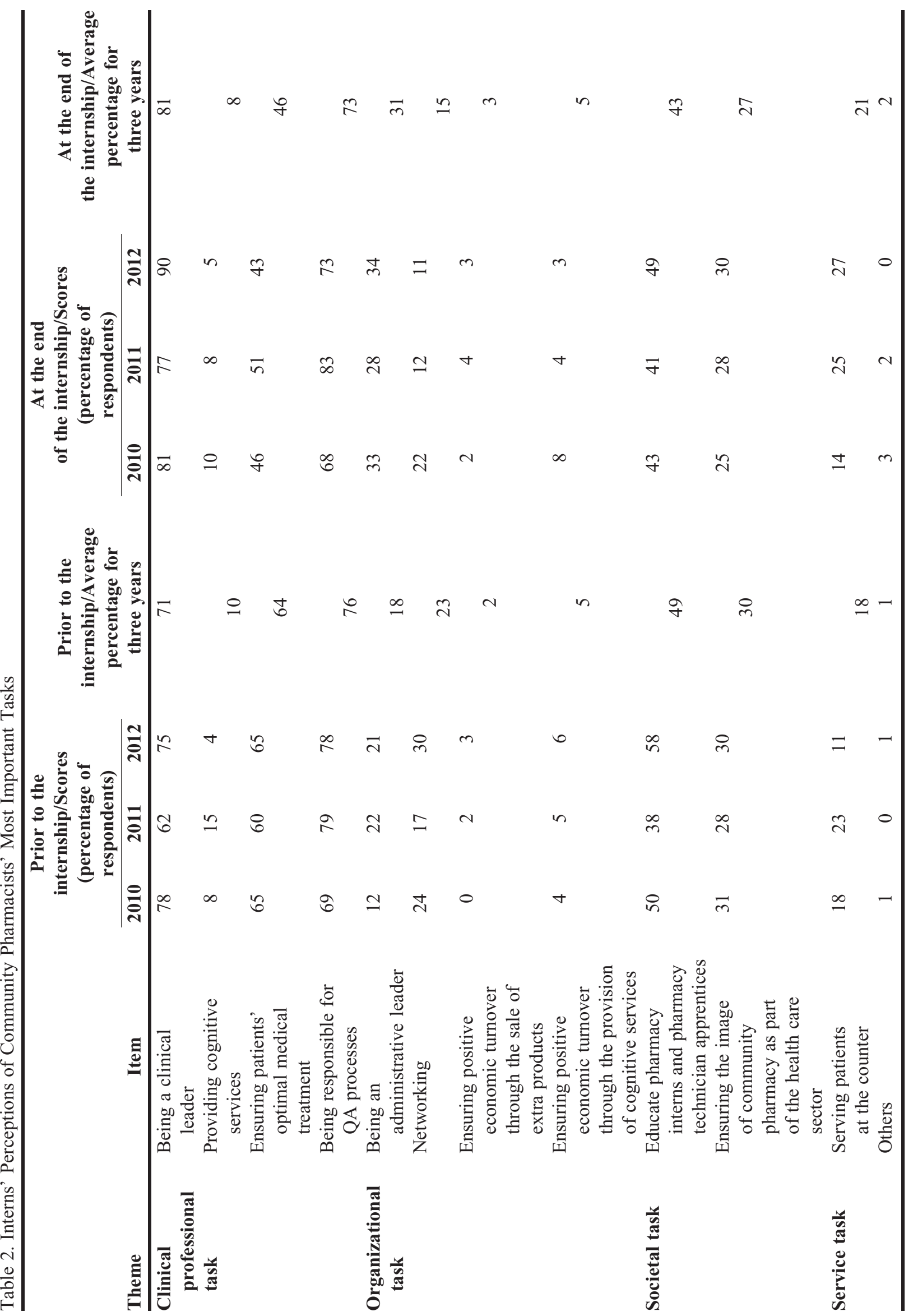


American Journal of Pharmaceutical Education 2017; 81 (1) Article 10.

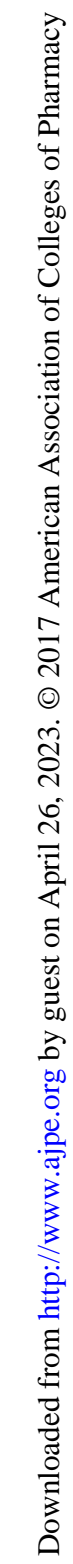

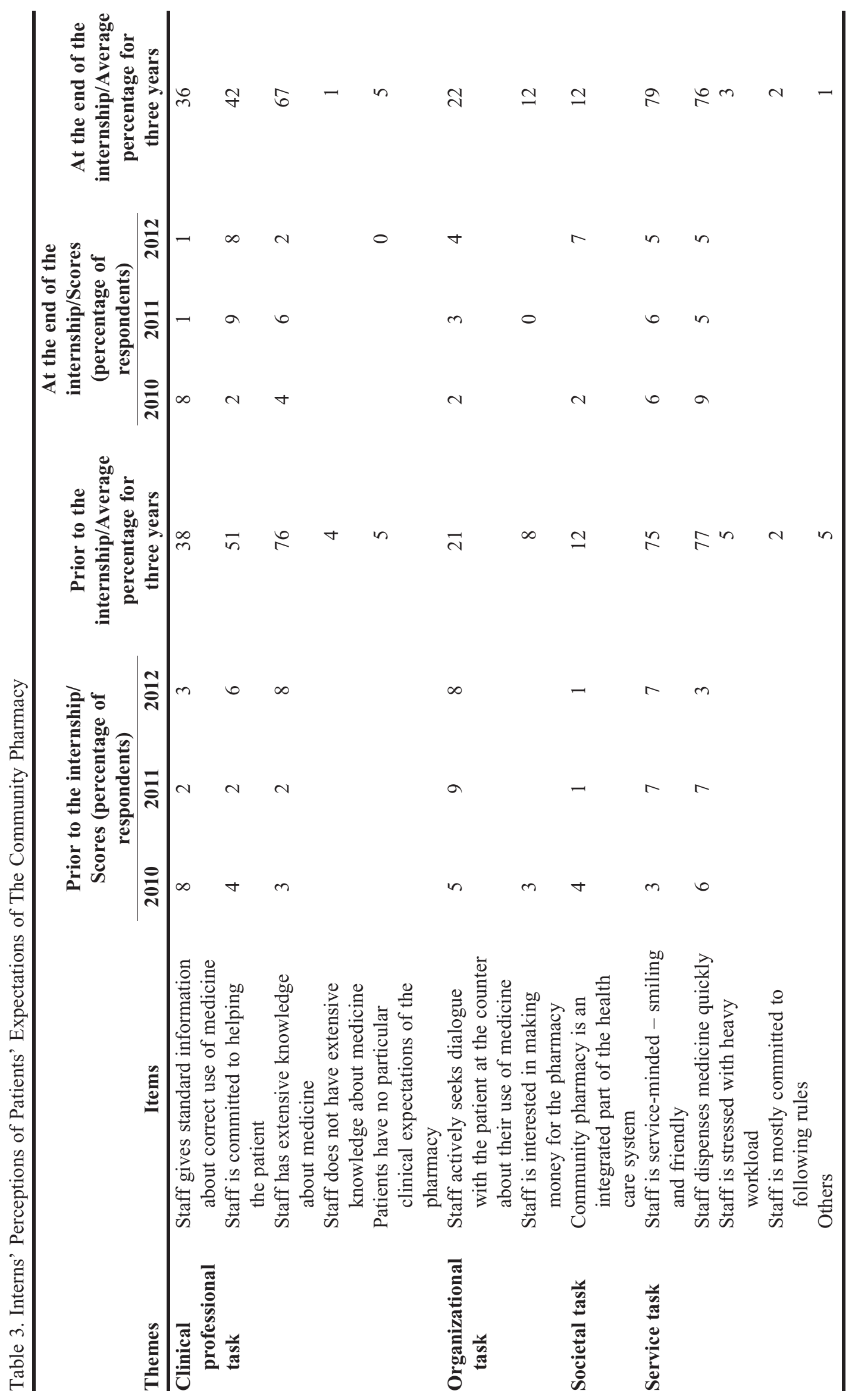




\section{American Journal of Pharmaceutical Education 2017; 81 (1) Article 10.}

Table 4. Supervisors' Perceptions of Community Pharmacists' Most Important Tasks

\begin{tabular}{lcc}
\hline & $\begin{array}{c}\mathbf{2 0 1 1} \\
\text { Scores (\%) }\end{array}$ & $\begin{array}{c}\mathbf{2 0 1 2} \\
\text { Scores (\%) }\end{array}$ \\
\hline Being an administrative leader & 34 & 42 \\
$\begin{array}{l}\text { Establishing contact between } \\
\text { GP and pharmacy }\end{array}$ & 21 & 1 \\
$\begin{array}{l}\text { Being a clinical leader } \\
\text { Being responsible for QA } \\
\quad \text { processes }\end{array}$ & 92 & 95 \\
Teaching pharmacy interns & 24 & 25 \\
$\quad \begin{array}{l}\text { and pharmacy technician } \\
\text { apprentices }\end{array}$ & 14 & 4 \\
$\begin{array}{l}\text { Promoting a clinical image } \\
\text { of the pharmacy }\end{array}$ & 8 & 7 \\
\hline
\end{tabular}

between pharmacy interns and their supervisors and between supervisors and customers. Interns' perception of customers' expectations of the pharmacy were more aligned with the customers' expectations than with the supervisors' perceptions, and this alignment was reinforced during the internship period. This might be because the interns, through their first experience of working at the pharmacy counter, recognize the importance of good interactions with customers. Supervisors are no longer subject to such first-time experiences; they are accustomed to the customers. Here, we see an excellent example of Wenger's notions of learning as becoming and learning as experiencing. ${ }^{12}$

This study confirmed that pharmacy staff members' views about the role of the pharmacy differ from customers' expectations. A major discrepancy was identified regarding the issue of customers' expectations about service. A small discrepancy regarding clinical tasks also was identified. The role of pharmacy internship placement in aligning the attitudes of interns with those of their supervisors was a more complex process than expected. During the internship, interns became more aligned with regard to the clinical tasks of the pharmacists but increasingly disagreed with supervisors' perceptions of customers' expectations of the pharmacy. These results appear to be in line with previous findings. ${ }^{8}$ One potential explanation for the increase in interns' perceptions of pharmacists' clinical role over the course of the internship is what Lave and Wenger ${ }^{13}$ and Sørensen and Haugbølle ${ }^{9}$ call "legitimate peripheral participation."

The area in which interns were increasingly aligned with each other during the internship (and increasingly misaligned with their supervisors) was customers' expectations of service. During the internship, interns not only have contact with pharmacy staff members but also with customers. The Copenhagen University curriculum requires pharmacy interns to spend nine of the 26 weeks engaged in the daily work of the pharmacy, which primarily consists of serving customers at the counter. Hence, customer contact is a large part of the internship. The results of this study indicate that interns are as much influenced by their interaction with customers during their internship as they are by their interaction with pharmacy staff members. Based on the results of our study, we agree with Wenger's claim that even though learning is a trajectory into a community of practice, it equally (or even more importantly) concerns creating an identity (learning as becoming). ${ }^{12,14}$ According to Wenger, learning is the foundation of what it means to be human. ${ }^{14}$ Thus, one cannot necessarily expect an intern to simply copy the supervisor's way of thinking and acting (learning as belonging and learning as doing). We found that interns are influenced by many other factors including examination requirements, the two weeks of courses at the university during their internship period, other interns, mass media, social media, and pharmacy staff members.

According to the results, the pharmacy internship appears to be minimally effective in reinforcing pharmacy interns' existing perceptions and beliefs. In contrast, interns become more perceptive of customers' needs and expectations through their exposure to customers and the day-today work environment of the pharmacy.

Because the questions on the intern survey reflected pre-established themes, while the interviews with customers and supervisors included open-ended questions, some caution should be taken when comparing the results of these two methods of data gathering. Specifically, interns' scores cannot be directly compared with customers' and supervisors' scores. Interns might have responded differently if they had been asked questions in a face-to-face interview; thus, the basis for the construction of the themes differed. However, because of their inexperience, we assumed that interns would have had difficulty expressing their perception of the most important tasks of pharmacies and pharmacists prior to the internship. Hence, we used predeveloped themes to explore interns' perceptions in depth. Additionally, the unequal distribution of items under the different themes poses limitations to interpretation, and the pre-developed themes pose the risk of steering answers in a particular direction. However, although respondents could answer "others" several time, they rarely selected this option.

Aside from the advantages described above, interns' collection of data from customers also poses the possibility of bias, as the interns had minimal training in and experience with interviewing. Interns', supervisors', and 


\section{American Journal of Pharmaceutical Education 2017; 81 (1) Article 10.}

customers' answers showed relatively little variance from year to year, thereby illustrating consistency in the data and the high validity of the results.

\section{CONCLUSION}

In an attempt to understand how the pharmacy internship influences interns' attitudes toward the role of the pharmacists and the pharmacy, this paper presents the results of a study with 395 pharmacy interns, 96 supervisors and 285 customers (the two latter groups were interviewed, and the former group responded to two questionnaires). During their formal training at the university, interns seemed to have constructed an understanding that customers' expectations of pharmacy services are high - a perception that is further consolidated during the internship, but increasingly unaligned with supervisors' perceptions. The study also found that interns perceive more and more the same during the internship. Additionally, interns' perceptions appear to be aligned with those of their supervisors, as both groups rated "being a clinical leader" as their most important task. However, interns' perceptions of customers' expectations of the pharmacy were more aligned with customers than with pharmacists, especially regarding the importance of service in the pharmacy encounter. The results of the study imply that the influence of the pharmacy internship on interns' perception of the roles of pharmacy and pharmacists in society is the result of a complex learning process based on both individual and social processes. More research is needed to better understand this phenomenon and its implications for the design of internship programs.

\section{REFERENCES}

1. Traulsen JM, Almardóttier AB. Pharmaceutical policy and the pharmacy profession. Pharm World Sci. 2005;27(5):359-363.

2. Renberg T, Törnquist KW, Sporrong SK, Lindblad AK, Tully MP. Pharmacy users' expectations of pharmacy encounters: a Q-methodological study. Health Expect. 2011;14(4):361-373.

3. Assa-Eley M, Kimberlin CL. Using Interpersonal perception to characterize pharmacists' and patients' perceptions of the benefits of pharmaceutical care. Health Commun. 2005;17(1):41-56.
4. Hibbert D, Bissell P, Ward PR. Consumerism and professional work in the community pharmacy. Sociol Health Ill. 2002;24(1): 46-65.

5. Perraudin C, Brion F, Bourdon O, Pelletier-Fleury N. The future of pharmaceutical care in France: a survey of final-year pharmacy students' opinions. BMC Clin Pharmacol. 2011;11(6):1-8.

6. Siracuse MV, Schondelmeyer SW, Hadsall RS, Schommer JC. Third-year pharmacy students' work experience and attitudes and perceptions of the pharmacy profession. Am J Pharm Educ. 2008; 72(3):1-9.

7. Wallman A, Gustavsson M, Lindblad ÅK, Ring L. An exploration of how students learn in a pharmacy internship. Pharm Educ. 2011; 11(1):177-182.

8. Guirguis LM, Chewning BA, Kieser MA. A randomized controlled trial to evaluate the impact of structured patient interactions on pharmacy students' counselling behaviours and attitudes. Int J Pharm Pract. 2009;17(1):53-60.

9. Sørensen EW, Haugbølle LS. Using an action research process in pharmacy practice research: a cooperative project between university and internship pharmacies. Res Social Adm Pharm. 2008;4(4):384-401.

10. Walman A. Pharmacy Internship: Student's Learning in a Professional Practice Setting [doctoral thesis]. Uppsala, Sweden: Uppsala University. 2010. ISBN 978-91-554-7725-7.

11. Felstead A, Fullar A, Unwin L, Ashton D, Butler P, Lee T. Surveying the scene: learning metaphors survey design and the workplace context. J Educ Work. 2005;18(4):359-383.

12. Wenger E. Communities of Practice: Learning, Meaning and Identity. Cambridge, England: Cambridge University Press; 1998.

13. Lave J, Wenger E. Situated Learning. Legitimate Peripheral Participation. Cambridge, England: Cambridge University Press; 1991.

14. Wenger E. Professional learning in landscapes of practice: recent developments in social learning theory. Copenhagen University Keynote Speech. 2013.

15. Sørensen EW, Herborg H, Haugbølle LS, Tomsen D. Improving situated learning in pharmacy internship. Pharm Educ. 2005; 5(3/4):223-234.

16. Traulsen JM. Do patient's views and expectations of pharmacists match those of the profession? Paper presented at: FIP- World Congress of Pharmacy and Pharmaceutical Sciences; August 28-September 2, 2010; Lisbon, Portugal.

17. American Pharmaceutical Association. Pharmacy practice activity classification: a classification of licensed, practising pharmacists aross the continuum of healthcare delivery systems. 1998.

18. Kaae S, Traulsen JM, Nørgaard LS. Customer interest in and experience with various types of pharmacy counselling: a qualitative study. Health Expect. 2012;17(6):852-862. 